\title{
Pré-tratamento com cloro e ozônio para remoção DE CIANOBACTÉRIAS
}

\section{Pre-treatMent With CHLORINe AND OZONE FOR REMOVAL OF THE CYANOBACTERIA}

\begin{abstract}
RENATA IZA MONDARDO
Bacharel em Química (UFSC). Mestre em Engenharia Ambiental (UFSC) .Doutoranda do Programa de Pós-Graduação em Engenharia Ambiental do Departamento de Engenharia Sanitária e Ambiental da UFSC

\author{
MAURÍCIO LUIZ SENS \\ Engenheiro Sanitarista (UFSC). Doutor em Engenharia Ambiental (Université de Rennes I / França).Professor Titular \\ do Departamento de Engenharia Sanitária e Ambiental da UFSC
}

\section{Luiz CARLos de MELO FILHO}

Engenheiro Sanitarista (UFSC). Especialista em Engenharia de Saúde Pública (ENSP /FIOCRUZ). Mestre em Engenharia Ambiental (UFSC). Doutorando do Programa de Pós-Graduação em Engenharia Ambiental da UFSC

Recebido: 05/07/05 Aceito: 06/08/06
\end{abstract}

\section{RESUMO}

O presente trabalho tem como objetivo investigar o desempenho da ozonização e da cloração utilizadas na pré-oxidação de água, com elevada concentração de microalgas e cianobactérias, a ser submetida à Filtração Direta Descendente, seguida de desinfecção por cloro, avaliando a qualidade da água produzida, sobretudo no que se refere à remoção de fitoplâncton, à formação de trialometanos e aos testes toxicológicos. Os ensaios, em escala piloto, realizados com a pré-ozonização, apresentaram melhores resultados quando comparados aos realizados com a pré-cloração. Em relação aos trialometanos, por exemplo, a aplicação da pré-ozonização com $2 \mathrm{mgO}_{3} / \mathrm{L}$ reduziu em até $50 \%$ a formação desses compostos quando comparado ao emprego da pré-cloração. $\mathrm{O}$ emprego da ozonização demonstrou ser uma excelente alternativa para o pré-tratamento de água com elevada concentração de microalgas e cianobactérias que utiliza a técnica da filtração direta como processo de potabilização, produzindo água filtrada condizente com o padrão de potabilidade estabelecidos pela Portaria 518/GM do Ministério da Saúde.

PALAVRAS-CHAVE: Tratamento de água, filtração direta, pré-ozonização, cianobactérias, trialometanos

\begin{abstract}
The present work aims at investigating the performance of ozonation and chlorination used in the pre-oxidation of water with high microalgae and cyanobacteria concentration to be submitted to downflow direct filtration followed by chlorine disinfection, and evaluating the quality of the water produced, especially with regard to phytoplankton removal, trihalomethane formation, and toxicological tests. The pilot scale tests carried outwith the pre-ozonation exhibited better results when compared to the results from the pre-chlorination tests. As to the trihalomethanes, for example, the application of pre-ozonation with $2 \mathrm{mgO} / \mathrm{L}$ reduced in $50 \%$ the formation of these compounds whencompared to the application of pre-chlorination. The application of ozonation was shown to be an excellent alternative for pre-treating water with high concentration of microalgae and cyanobacteria when using the direct fi ltration technique for producing water that complies with the drinking water standards established by Portaria GM 518-25/03/2004 of the Brazilian Health Department (Ministério da Saúde).
\end{abstract}

KEYWORDS: Water treatment, direct fil ltration, pre-ozonation, cyanobacteria, trihalomethanes.

\section{INTRODUÇÃO}

Muitas estações de tratamento de água (ETA) apresentam, atualmente, sérios problemas operacionais decorrentes de inadequadas tecnologias de tratamento às características do manancial de água explorado. A causa dessa inadequabilidade se deve à falta de um prévio monitoramento da qualidade da água do manancial, antes da elaboração do projeto, ou pela falta de proteção do manancial, possibilitando assim açōes que modifiquem suas características. Além do problema anteriormente mencionado, os processos convencionais de tratamento não são capazes de remover traços de micropoluentes, de origem química ou biológica, que podem causar diversas doenças crônicas se ingeridas por longo tempo. Tal limitação deveria obrigar que a captação da água fosse realizada em mananciais isentos desses micropoluentes ou, nos casos em que isso não seja possível, métodos de tratamento mais avançados devem ser aplicados.

No Brasil, a presença, em seus mananciais, de microalgas e cianobactérias é um grave problema enfrentado pelas ETAs que utilizam a tecnologia de tratamento convencional ou Filtração Direta. Ou seja, dependendo da espécie e do número de indivíduos, há a redução da duração das carreiras de filtração, comprometendo seriamente a qualidade $\mathrm{da}$ água produzida, principalmente devido 
à liberação de metabólicos. Atualmente, são conhecidos aproximadamente 150 gêneros de cianobactérias, sendo que cerca de 46 espécies já foram identificadas como potencialmente tóxicas a vertebrados. (Cunha et al, 2003).

A pré-cloração é uma prática realizada em muitos sistemas de tratamento de água visando à remoção/inativação de microalgas e cianobactérias. Entretanto, alguns problemas foram observados na utilização desse pré-tratamento em mananciais com elevadas concentraçôes de fitoplâncton, sobretudo a formação de subprodutos clorados, como por exemplo, os trialometanos (THM), os quais, segundo Macedo et al (1995), são considerados carcinogênicos, e da liberação de metabólicos, que podem ser potencialmente tóxicos.

O ozônio tem sido utilizado extensivamente como oxidante e desinfetante em tratamento de águas superficiais para a produção de água potável na Europa e está cada vez mais, sendo aplicado como pré-oxidante nos Estados Unidos.

O presente trabalho tem como objetivo investigar o desempenho do ozônio e do cloro, utilizados na pré-oxidação de água, com elevada concentração de microalgas e cianobactérias, a ser submetida à tecnologia da Filtração Direta Descendente, seguida de desinfecção por cloro para avaliar a qualidade da água após tratamento completo, principalmente, no que se refere à formação de THM.

\section{METODOLOGIA}

As investigações experimentais foram realizadas no Laboratório de Águas da Lagoa do Peri (L.A.L.P.), situado na estação de tratamento de água da Companhia Catarinense de Águas e Saneamento (CASAN), sendo conduzidas em três etapas: caracterização da água do manancial; ensaios em bancada objetivando as dosagens ótimas dos préoxidantes estudados (cloro e ozônio), coagulante e $p H$ de coagulação; ensaios em piloto contínuo utilizando as dosagens ótimas, anteriormente, determinadas.

\section{Descrição do sistema piloto}

O sistema piloto foi alimentado por gravidade, com água natural da Lagoa do Peri. Inicialmente, a água bruta era direcionada para uma câmara de carga de nível constante, dotada de um orifício calibrado de modo a fornecer uma vazão de $400 \mathrm{~L} / \mathrm{h}$ para as unidades de pré-oxidação. Registros permitiam a alternância entre as unidades de précloração e pré-ozonização.

Pré-cloraçãa: baseada nos ensaios de bancada, a pré-cloração foi realizada com as dosagens de 2,5; 3,0 e 3,5 mg/L de cloro, num tempo de contado aproximado de 5 minutos, obtido através de um reator formado por mangueira de $40 \mathrm{~mm}$ e 50 metros de comprimento.

Pré-ozonização: de acordo com os ensaios de bancada, a pré-ozonização foi realizada com as dosagens de 1,5; 2,0 e $2,5 \mathrm{mg} / \mathrm{L}$ de ozônio. O gás contendo ozônio era produzido por um ozonizador de laboratório (modelo LABO-6LO/, com capacidade média de produção de $22 \mathrm{~g} \mathrm{O}_{3}$ /hora) e transferido para a massa líquida numa coluna clássica de bolhas, através de difusores porosos situados na base da coluna, formando um sistema de contato gáslíquido do tipo contra corrente. As concentrações de ozônio foram determinadas pelo Método Iodométrico, e a eficiência de transferência foram obtidas pela diferença entre as concentraçōes de ozônio na aplicação (feed-gás) e na saída da coluna (off-gás).

Mistura Rápida: a água pré-oxidada foi recalcada por bomba centrífuga (1/2 CV) até uma segunda câmara de carga de nível constante, dotada de um orifício calibrado de modo a fornecer uma vazão de $317 \mathrm{~L} / \mathrm{h}$ para a unidade de mistura rápida. A mistura rápida era feita numa pequena câmara, onde as soluçōes de sulfato de alumínio (2\%) e óxido de cálcio $(0,2 \%)$ foram aplicadas, através de bombas dosadoras, em concentraçôes determinadas nos ensaios de bancada. A dispersão das soluções era feita por um agitador mecânico, dotado de controle eletrônico de rotação e paletas recambiáveis, com gradiente $(\mathrm{G})$ de $1200 \mathrm{~s}^{-1}$.

Filtração Direta: após receber a adiçấo de coagulante, a água passava por um filtro de fluxo descendente, construído em aço inoxidável, com seção quadrada de $20 \mathrm{~cm}$ de lado. $\mathrm{O}$ material filtrante granular era formado de camada única de antracito com $1,43 \mathrm{~m}$ de espessura (diâmetro dos grãos: $3,00 \mathrm{~mm} /$ coeficiente de desuniformidade $\mathrm{CD}=1,1$ ), e camada suporte de $35 \mathrm{~cm}$ de espessura com grãos de diâmetro, variando entre 1,60 a $19 \mathrm{~mm}$. A taxa de filtração era cons- tante, na ordem de $200 \mathrm{~m}^{3} / \mathrm{m}^{2}$.dia, e a carga hidráulica variável.

A Figura 1 que apresenta o esquema geral da instalação experimental construída no L.A.L.P., composta das unidades de pré-oxidação (cloração e ozonização) e filtração direta descendente.

\section{Parâmetros de controle}

Amostras de água filtrada foram coletadas após 4 horas de operação do tratamento e respeitando-se a produção de água com turbidez inferior a 1,0 uT. Alguns ensaios sem pré-oxidação foram realizados para efeito de comparação. Após a filtração, as amostras recebiam a adição de $1,0 \mathrm{mg} / \mathrm{L}$ cloro ativo (hipoclorito de sódio), com tempo de contato de 30 minutos para simular a etapa de desinfecção, sendo posteriormente analisadas, segundo os seguintes parâmetros de controle: $\mathrm{pH}$ (pHmetro HACH); cor aparente, THM (analisado após 24 horas de contato - espectrofotômetro HACH 2010); clorofila a /método de NUSCH (espectrofotômetro DR/4000 HACH); fitoplâncton (microscópio invertido); turbidez (turbidímetro HACH 2100P); temperatura (termômetro de mercúrio); toxicidade - Compostos Halogenados Multagênicos (genotoxicidade avaliada através da formação de micronúcleos em células de peixes expostos às águas produzidas - microscopia óptica). Os ensaios foram realizados em triplicatas e, a partir dos valores e das médias, foram construídos os gráficos e as tabelas.

\section{RESULTADOS E DISCUSSOOES}

\section{Qualidade da água da Lagoa do Peri}

A água da Lagoa do Peri apresentou uma certa regularidade entre os parâmetros observados durante o período de monitoramento (abril de 2002 a março de 2003). As variaçōes mais significativas aconteceram na turbidez, $\mathrm{pH}$, cor e organismos fitoplanctônicos, sobretudo a partir de outubro, o que causou dificuldades operacionais na estação da Lagoa do Peri. A Tabela 1 apresenta os valores médios dos parâmetros analisados no período de monitoramento da qualidade das águas da Lagoa do Peri. 


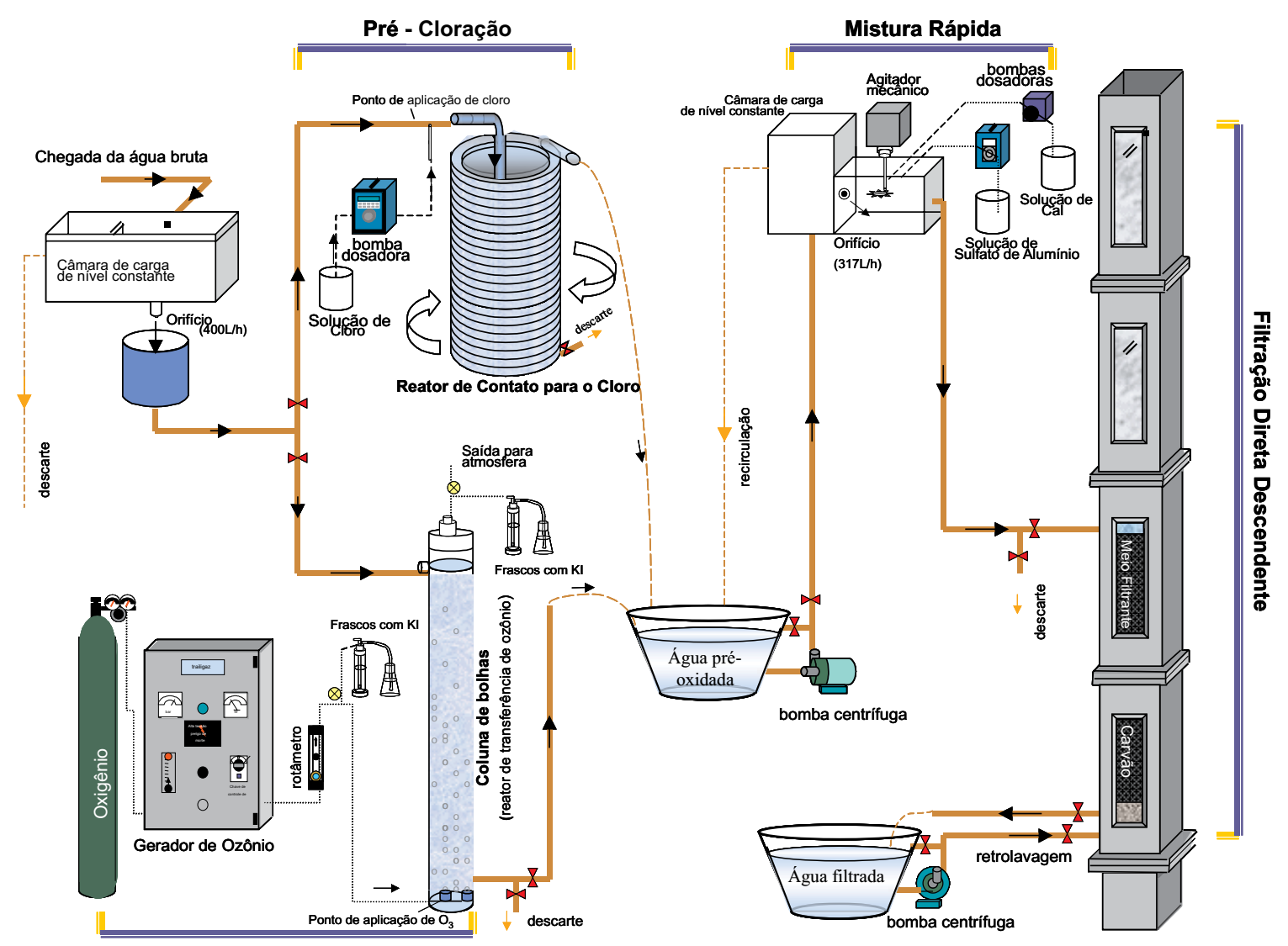

Pré - Ozonização

Figura I - Esquema geral do Sistema Piloto de Tratamento

Tabela I - Característica da água bruta durante o período da investigação experimental

\begin{tabular}{cccccc}
\hline Parâmetro & $\begin{array}{c}\text { Valor } \\
\text { mínimo }\end{array}$ & $\begin{array}{c}\text { Valor } \\
\text { máximo }\end{array}$ & Parâmetro & $\begin{array}{c}\text { Valor } \\
\text { mínimo }\end{array}$ & $\begin{array}{c}\text { Valor } \\
\text { máximo }\end{array}$ \\
\hline Alcalinidade $\left(\mathrm{mg} / \mathrm{L} \mathrm{CaCO}_{3}\right)$ & 6,2 & 11,0 & Nitrato $\left(\mathrm{mg} / \mathrm{L} \mathrm{NO}_{3}{ }^{-}\right)$ & 0,017 & 0,8 \\
Cloretos $\left(\mathrm{mg} / \mathrm{L} \mathrm{Cl}^{-}\right)$ & 11,4 & 22,0 & Nitrogênio $\left(\mathrm{mg} / \mathrm{L} \mathrm{NH}_{4}\right)$ & 0,01 & 0,16 \\
Clorofila-a $(\mu \mathrm{gg} / \mathrm{L})$ & 2,75 & 41,39 & Ortofosfato $\left(\mathrm{mg} / \mathrm{L} \mathrm{PO}_{4}^{3-}\right)$ & 0,02 & 0,07 \\
Condutividade $(\mu \mathrm{S} / \mathrm{cm})$ & 50 & 80 & Oxigênio Dissolvido $(\mathrm{mg} / \mathrm{L})$ & 6,44 & 9,8 \\
Cor aparente $(\mathrm{uH})$ & 50 & 85 & pH & 6,20 & 7,14 \\
Cor verdadeira $(\mathrm{uH})$ & 03 & 10 & Temperatura $\left({ }^{\circ} \mathrm{C}\right)$ & 23,0 & 31,0 \\
COT $(\mathrm{mg} / \mathrm{L})$ & 5,5 & 7,1 & Trialometanos $(\mu \mathrm{g} / \mathrm{L})$ & 32 & 52 \\
Dureza total $\left.(\mathrm{mg} / \mathrm{L} \mathrm{CaCO})_{3}\right)$ & 6,5 & 13,6 & Turbidez $(\mathrm{uT})$ & 3,2 & 7,8 \\
Fitoplâncton Total $(\mathrm{Indivíduos} / \mathrm{mL})$ & 4129 & 273880 & & & \\
$\left(\mathrm{~mm}^{3} / \mathrm{L}\right)$ & 4,56 & 20,35 & & &
\end{tabular}


As espécies dominantes de fitoplâncton na Lagoa do Peri, no período de monitoramento, foram Cylindrospermopsis raciborskii e Pseudanabaena galeata (cianobactérias filamentosas), produtoras de hepatoxinas e neurotoxinas, toxinas estas que causam intoxicações agudas e crônicas, atingindo as células do fígado e o Sistema Neuromuscular, podendo levar à morte de animais em minutos, horas e dias. De acordo com o observado nas mostras analisadas, a espécie Cylindrospermopsis raciborskii, dominante na maior parte do ano, é limitada pelas baixas temperaturas. A queda da sua densidade favorece o crescimento de Pseudanabaena sp., suas prováveis competidoras. As cianobactérias encontradas nas águas da Lagoa do Peri são potencialmente tóxicas e podem representar sérios riscos à saúde do ser humano. A distribuição do fitoplâncton na água bruta da Lagoa do Peri é facilmente observada, no gráfico apresentado, na Figura 2.

\section{Ensaios realizados no sistema piloto com escoamento contínuo}

De posse dos resultados dos ensaios de bancada que determinaram as dosagens de $20 \mathrm{mg} / \mathrm{L}$ de sulfato de alumínio para os ensaios feitos com a pré-ozonização, e $30 \mathrm{mg} / \mathrm{L}$ para os ensaios com a pré-cloração (dosagens adquiridas através da construção do diagrama de coagulação, de forma a manter o mesmo padrão de qualidade da água) e as dosagens adequadas dos oxidantes investigados (cloro e ozônio), foram realizados os ensaios com escoamento contínuo no Sistema Piloto. O sistema de tratamento era composto das etapas de pré-oxidaçãoo, coagulação, filtração de escoamento descendente e desinfecção por cloro. A Tabela 2 apresenta os valores médios dos ensaios realizados com pré-ozonização e précloração no sistema piloto de filtração direta descendente.

As águas submetidas ao pré-tratamento com ozônio apresentaram melhor qualidade em comparação às águas dos ensaios que utilizaram a précloração. Em relação à redução da concentração de clorofila $a$ e fitoplâncton, por exemplo, a pré-ozonização realizada com a dosagem de $2,0 \mathrm{mgO}_{3} / \mathrm{L}$ produziu água, após tratamento completo, com concentração de clorofila $a$ não detectada pelo método analítico utiliza-

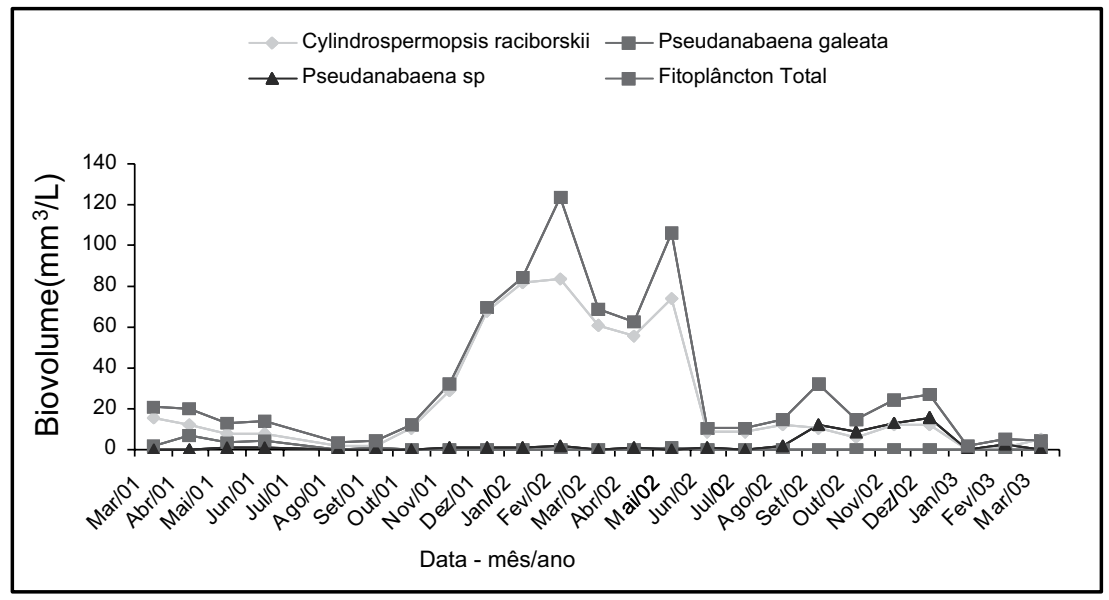

Figura 2 - Distribuição do Fitoplâncton (Biovolume) na água da Lagoa do Peri durante o monitoramento março de 2001 a março de 2003

do, e densidade de fitoplâncton inferior a $600 \mathrm{Ind} . / \mathrm{mL}$ ou $0,04 \mathrm{~mm}^{3} / \mathrm{L}$

\section{Desempenho dos pré- oxidantes em relação à remoção de fitoplẩncton}

Os resultados demonstraram que a realização da pré-ozonização com as dosagens de ozônio, utilizadas nesta pesquisa $\left(1,5 ; 2,0 ; 2,5 \mathrm{mgO}_{3} / \mathrm{L}\right)$, removeu o fitoplâncton presente nas amostras da água bruta, em mais de $99 \%$, superando em muito a pré-cloração, que com a dosagem de $2,5 \mathrm{mgCl}_{2} / \mathrm{L}$ não alcançou $55 \%$ de remoção. Observa-se também que o número de fitoplâncton é menor nos ensaios, onde não foi feita a pré-oxidação quando comparado aos ensaios com a pré-cloração. Tal resultado pode ser explicado por uma possível interferência do cloro no mecanismo de coagulação-química, prejudicando, assim, a remoção de fitoplâncton no processo de clarificação da água.

A Figura 3 apresenta o gráfico de remoção de fitoplâncton dos ensaios realizados com e sem pré-oxidação para os dois oxidantes investigados.

\section{Desempenho dos pré- oxidantes em relação à remoção de trialometanos}

A Figura 4 apresenta os resultados da concentração de trialometanos dos ensaios, utilizando os dois oxidantes investigados, com e sem desinfecção após o tratamento completo.

Os resultados mostraram que as águas do manancial apresentavam níveis significativos de THM, sendo isto bastante curioso, já que esses compostos raramente existem, de forma natural, nas águas superficiais, pois são formados geralmente no tratamento após a cloração das águas.

Os precursores de THM aparecem na água bruta devido à decomposição do material vegetal existente nos leitos de rios e lagos, sendo mais abundantes em mananciais protegidos e que possuem maior quantidade de vegetação em suas margens. (Macedo et al, 1995). E, segundo Fonseca (1991), a concentração de íon cloreto $(\mathrm{Cl})$, em lagoas costeiras, é influenciada fortemente pelos aerossóis marinhos, sendo que a sua intensidade depende da distância do mar.

A Lagoa do Peri está localizada em uma área de preservação (Parque Municipal da Lagoa do Peri), recebendo aporte de material vegetal proveniente da mata que a rodeia e, por sua grande proximidade do mar, é influenciada predominantemente por ventos marinhos. Acredita-se que tais situações justifiquem a concentração de THM, encontrada nas águas do manancial.

No Brasil, a Portaria ${ }^{\circ} 518$ (Ministério da Saúde) estabelece o valor máximo permitido para a concentração

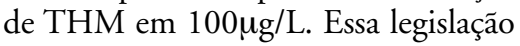
ressalta ainda que esse valor poderá ser revisto, em função de estudos toxicológicos, que ainda estão em período de conclusão. Em 1998, a EPA reduziu em $20 \%$ os valores preconizados para THM, passando para $80 \mu \mathrm{g} / \mathrm{L}$, como concentração máxima aceitável. Segundo Ferreira Filho (2001), espera-se uma redução futura para $40 \mu \mathrm{g} / \mathrm{L}$.

$\mathrm{O}$ desempenho dos ensaios realizados com pré-ozonização em relação à 
Tabela 2 - Qualidade da água bruta e tratada precedida de oxidação

\begin{tabular}{|c|c|c|c|c|c|c|c|c|}
\hline \multirow[t]{3}{*}{$\begin{array}{c}\text { Condiçōes de } \\
\text { coagulaçãáo } \\
\text { parâmetros }\end{array}$} & \multicolumn{4}{|c|}{$\begin{array}{c}\text { Pré-Tratamento: Ozonização } \\
\text { Dosagem Al2 }\left(\mathrm{SO}_{4}\right)_{3}=20 \mathrm{mg} / \mathrm{L} \\
\mathrm{pH} \text { de Coagulaçấo }=5,5 \text { a 5,80 }\end{array}$} & \multicolumn{4}{|c|}{$\begin{array}{c}\text { Pré- Tratamento: Cloração } \\
\text { Dosagem } \mathrm{Al}_{2}\left(\mathrm{SO}_{4}\right)_{3}=30 \mathrm{mg} / \mathrm{L} \\
\mathrm{pH} \text { de Coagulaçâo }=5,5 \text { a 5,84 }\end{array}$} \\
\hline & Água & Água com & Água com & Água com & Água & Água com & Água com & Água com \\
\hline & Bruta & $1,5 \mathrm{mgO}_{3} / \mathrm{L}$ & $2,0 \mathrm{mgO}_{3} / \mathrm{L}$ & $2,5 \mathrm{mgO}_{3} / \mathrm{L}$ & Bruta & $2,5 \mathrm{mgCl}_{2} / \mathrm{L}$ & $3,0 \mathrm{mgCl}_{2} / \mathrm{L}$ & $3,5 \mathrm{mgCl}_{2} / \mathrm{L}$ \\
\hline $\begin{array}{c}\text { Cor Aparente } \\
\text { (uH) }\end{array}$ & 80 & 2 & 0 & 0 & 70 & 12 & 11 & 10 \\
\hline Turbidez (uT) & 6,0 & 0,44 & 0,26 & 0,40 & 4,93 & 0,86 & 0,78 & 0,68 \\
\hline $\begin{array}{c}\text { TTHMs } \\
(\mu \mathrm{g} / \mathrm{L})\end{array}$ & 39 & 43 & 38 & 40 & 37 & 52 & 83 & 98 \\
\hline Clorofila a $(\mu \mathrm{g} / \mathrm{L})$ & 40,88 & 2,94 & ND & ND & 36,77 & 4,04 & 3,73 & 3,30 \\
\hline $\begin{array}{l}\text { Fitoplâncton: } \\
\text { (Ind/mL) } \\
\left(\mathrm{mm}^{3} / \mathrm{L}\right)\end{array}$ & $\begin{array}{c}208134 \\
24,34\end{array}$ & $\begin{array}{l}4321 \\
0,27\end{array}$ & $\begin{array}{l}572 \\
0,04\end{array}$ & $\begin{array}{l}645 \\
0,05\end{array}$ & $\begin{array}{c}229577 \\
21,97\end{array}$ & $\begin{array}{r}96865 \\
10,24\end{array}$ & $\begin{array}{c}83963 \\
6,72\end{array}$ & $\begin{array}{c}44628 \\
3,06\end{array}$ \\
\hline
\end{tabular}

ND: Não Detectado

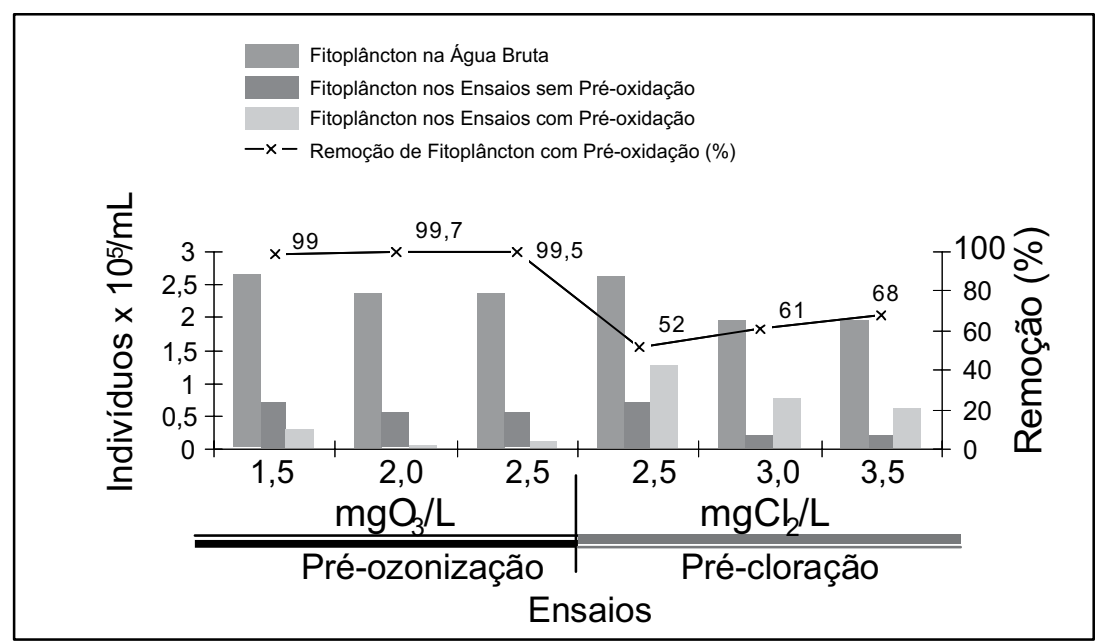

Figura 3 - Remoção de fitoplâncton com e sem pré-oxidação

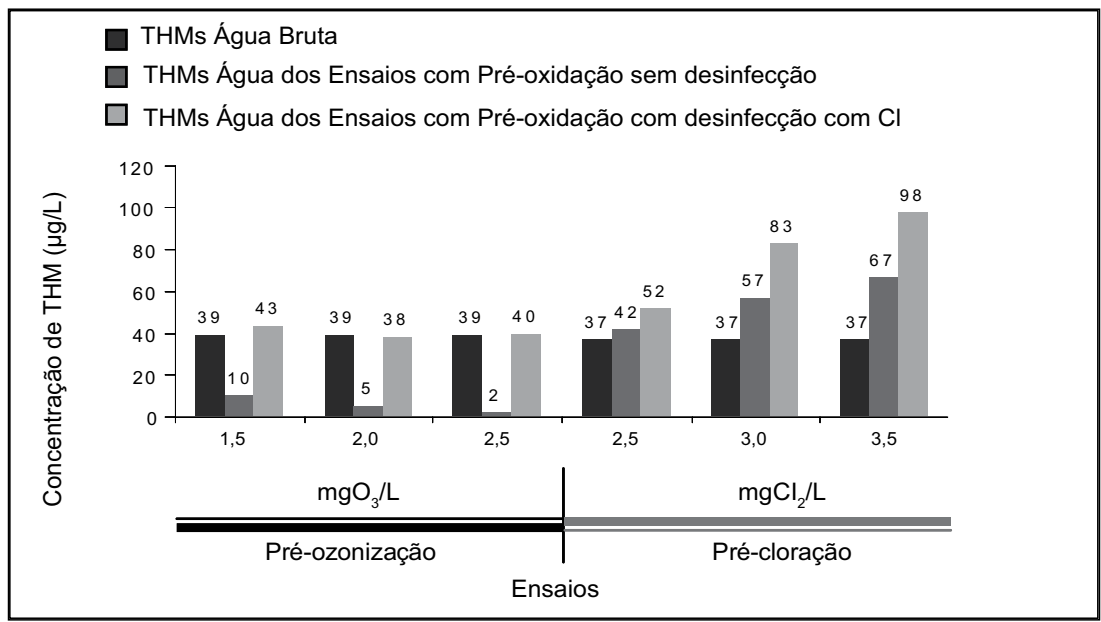

Figura 4 - Concentração de trialometanos dos ensaios com e sem pós-cloração (desinfecção) 
formação de trialometanos foi superior aos ensaios com pré-cloração, sendo que para todas as dosagens de ozônio a concentração de THM, após o tratamento completo (pré-oxidação - coagulação - filtração - desinfecção final com cloro), foi inferior a $40 \mu \mathrm{g} / \mathrm{L}$, o que vem ao encontro das tendências normativas futuras para tal composto. Quando a pré-oxidação e a desinfecção final são feitas somente com cloro, a concentração de THM aumenta significativamente, mesmo para doses de cloro na ordem de 3,0 a 3,5 mg/L, alcançando valores superiores a $98 \mu \mathrm{g} / \mathrm{L}$.

Os resultados também demonstraram que os ensaios com pré-ozonização e sem a realização da cloração na etapa da desinfecção obtiveram uma menor concentração de THM, valores inferiores a $12 \mu \mathrm{g} / \mathrm{L}$, bem menores que as concentraçôes dos mesmos ensaios realizados com a etapa de desinfecção, o que mostra a importância do cloro na formação dos trialometanos.

\section{Avaliação da atividade genotóxica dos compostos formados após a desinfecção}

Das técnicas citogenéticas disponíveis, o teste do micronúcleo tem sido bastante utilizado, como um teste primário para a detecção de genotoxicidade no ambiente aquático. (Vernier,1997). Os resultados obtidos nas análises citológicas, que avaliaram a freqüência de micronúcleos nos peixes expostos às águas estudadas, mostram que não houve formação de micronúcleos nos peixes expostos à água bruta, à água após tratamento completo sem pré-oxidação (branco) e à água após tratamento completo com pré-ozonização. No entanto, os peixes mantidos nas amostras de água produzidas, nos ensaios com pré-cloração, apresentaram formação de micronúcleos, principal- mente nos ensaios que utilizaram a dosagem de $3,5 \mathrm{mgCl}_{2} / \mathrm{L}$. A presença de micronúcleos pode ser considerada como uma indicação de ocorrência prévia de aberraçôes cromossômicas estruturais ou numéricas, em algum momento do ciclo de vida das células dos peixes utilizados nos testes realizados com a água pré-clorada após tratamento completo. A Figura 5 apresenta a formação de micronúcleos encontrados nas amostras pré-cloradas.

\section{CONCLUSÕES}

Com base na pesquisa realizada, concluiu-se que:

A ozonização utilizada como prétratamento à filtração direta descendente proporcionou melhores resultados de remoção de turbidez, cor aparente, clorofila a, números de fitoplâncton e menor formação de THM, comparados aos resultados dos ensaios com o emprego da pré-cloração, sendo que para todos esses parâmetros a água produzida esteve com concentraçôes abaixo das estabelecidas pela Portaria 518. (Ministério da Saúde, 2004).

$\mathrm{Na}$ avaliação da atividade genotóxica dos compostos formados após a etapa de desinfecção, os testes demonstraram que houve formação de micronúcleos apenas nos peixes submetidos à água pré-clorada, podendo indicar a ocorrência de aberraçôes cromossômicas estruturais nas células dos peixes, provocadas pelos compostos formados na pré-cloração.

A ozonização demonstrou ser uma excelente alternativa para o pré-tratamento de água com elevadas concentraçôes de microalgas e cianobactérias que utiliza a técnica da Filtração Direta Descendente, produzindo água condizente ao padrão de potabilidade. Essa combinação de processos também se mostrou bastante eficiente em relação à concentração de THM, mesmo após desinfecção por cloro, apresentando valores inferiores à tendência normativa futura para os referidos compostos. Entretanto, a combinação que empregou a pré-cloaração produziu água com concentração de THM no limite da Portaria 518. (Ministério da Saúde 2004).

\section{REFERÊNCIAS}

BRASIL, 2004. Portaria n ${ }^{\circ} 518$ de 25 de março de 2004 do Ministério da Saúde. Estabelece procedimentos e responsabilidades relativos ao controle e vigilância da qualidade da água para consumo humano e seu padrão de potabilidade, e das outras providências. In: Diário Oficial da União, n.59, p.166-176, Seção I. 26 de março 2004.

CUNHA, N. T. et al. Registro de toxinas paralisantes produzidas por Cylindrospermopsis raciborskii na regiäo sul do Brasil. In: 2० SIMPÓSIOBRASILEIRO DE ENGENHARIA AMBIENTAL, Itajaí, Santa Catarina. Anais...Itajaí, CD-ROM. 2003.

DI BERNADO, L. Algas e suas Influências na qualidade das águas e nas tecnologias de tratamento. ABES, Rio de Janeiro, 127p. 1995.

FERREIRA FILHO, S.S. Remoção de compostos orgânicos precursores de subprodutos da desinfeç̧ão e seu impacto na formação de trihalometanos em águas de abastecimento. Revista Engenharia Sanitária e Ambiental, v.6, n1 e 2, p. 53-60, Jan/Junho 2001

FONSECA, O. J. M. Aspecto limnológicos do lago Emboaba, planície costeira setentrional do rio Grande do Sul : morfometria, hidroquímica e degradação de Scircus californicus (C.A.MEYER) Stud. Tese (Doutorado em Ciências Biológicas). Universidade Federal de São Carlos. Programa de Pós-Graduação em Ecologia e Recursos Naturais. São Carlos, 247p. 1991.

MACEDO, J. A. B., ANDRADE, N.J. Formaçāo de Tribalometanos em águas cloradas para abastecimento público e indústria de alimentos. In: $13^{\circ}$ CONGRESSO NACIONAL DE LATICÍNIOS, Juiz de Fora, Anais... Juiz de Fora - MG: Centro de Pesquisa e Ensino Instituto Cândido Tostes, 1995. 324p. p.45-48, 1995.

MONDARDO, R. I. Influência da Pré-oxidação na Tratabilidade das Águas Via Filtração Direta Descendente em Manancial com elevadas Concentraçôes de Microalgas e Cianobactérias. Dissertação (Mestrado em Engenharia Ambiental). Universidade Federal de Santa Catarina. Programa de Pós-Graduação em Engenharia Ambiental. Florianópolis. 147p. 2004.

VERNIER, P. Detection of micronuclei in gill cells and hemocystes of mussels exposed to benzopirene. Mutation Research, v.390, p. 33 -44, 1997.

Endereço para correspondência:

Renata Iza Mondardo

Universidade Federal de Santa

Catarina - UFSC

Campus Universitário - Trindade

88040-900 Florianópolis - SC - Brasil

Tel.: (48) $3331-9470$

Email: mls@ens.ufsc.br 